\title{
Design of Active Magnetic Bearing Controllers for Rotors Subjected to Gas Seal Forces
}

\section{Lauridsen, Jonas Skjødt; Santos, IImar F.}

Published in:

Journal of Dynamic Systems, Measurement and Control

Link to article, DOI:

$10.1115 / 1.4039665$

Publication date:

2018

Document Version

Peer reviewed version

Link back to DTU Orbit

Citation (APA):

Lauridsen, J. S., \& Santos, I. F. (2018). Design of Active Magnetic Bearing Controllers for Rotors Subjected to Gas Seal Forces. Journal of Dynamic Systems, Measurement and Control, 140(9), [091015 ].

https://doi.org/10.1115/1.4039665

\section{General rights}

Copyright and moral rights for the publications made accessible in the public portal are retained by the authors and/or other copyright owners and it is a condition of accessing publications that users recognise and abide by the legal requirements associated with these rights.

- Users may download and print one copy of any publication from the public portal for the purpose of private study or research.

- You may not further distribute the material or use it for any profit-making activity or commercial gain

- You may freely distribute the URL identifying the publication in the public portal

If you believe that this document breaches copyright please contact us providing details, and we will remove access to the work immediately and investigate your claim. 


\title{
Design of Active Magnetic Bearing Controllers for Rotors Subjected to Gas Seal Forces
}

\author{
Jonas S. Lauridsen* \\ PhD student, Member of ASME \\ Department of Mechanical Engineering \\ Technical University of Denmark \\ Email: jonlau@mek.dtu.dk \\ IImar F. Santos ${ }^{\dagger}$ \\ Professor, Member of ASME \\ Department of Mechanical Engineering \\ Technical University of Denmark \\ Email: ifs@mek.dtu.dk
}

\begin{abstract}
Proper design of feedback controllers is crucial for ensuring high performance of Active Magnetic Bearing (AMB) supported rotor dynamic systems. Annular seals in those systems can contribute significant forces, which, in many cases, are hard to model in advance due to complex geometries of the seal and multiphase fluids. Hence, it can be challenging to design $A M B$ controllers that will guarantee robust performance for these kinds of systems. This paper demonstrates the design, simulation and experimental results of model based controllers for AMB systems, subjected to dynamic seal forces. The controllers are found using $\mathcal{H}_{\infty}$ and $\mu$ synthesis and are based on a global rotor dynamic model in-which the seal coefficients are identified in-situ. The controllers are implemented in a rotor-dynamic test facility with two radial $A M B s$ and one annular seal with an adjustable inlet pressure. The seal is a smooth annular type, with large clearance (worn seal) and with high pre-swirl, which generates signifcant cross-coupled forces. The $\mathcal{H}_{\infty}$ controller is designed to compensate for the seal forces and the $\mu$ controller is furthermore designed to be robust against a range of pressures across the seal. In this study the rotor is non-rotating. Experimental and simulation results show that significant performance can be achieved using the model based controllers compared to a reference decentralised Proportional Integral Derivative (PID) controller and robustness against large variations of pressure across the seal can be improved by use of robust synthesised controllers.
\end{abstract}

\footnotetext{
*Address all correspondence related to ASME style format and figures to this author.

${ }^{\dagger}$ Address all correspondence related to ASME style format and figures to this author.
}

\section{Introduction}

Uncompressible and compressible fluid flowing through very narrow gaps in annular seals can generate large forces. The influence of such liquid and gas seal forces on the lateral dynamics of rotating machines has been intensively investigated over several decades, by Fritz [1], Black [2, 3], Childs [4] and Nordmann [5] among others. Under high pressure and high pre-swirl flow conditions such aerodynamic forces can destabilize the rotating shaft, leading to high levels of lateral vibration. Catastrophic failures may occur in extreme cases of contact and rubbing between rotating shaft and seal.

The prediction of the dynamic behaviour of seals forces by means of mathematical models has been well documented in the literature over the past five decades. However, accurate prediction of seal forces remains an unresolved problem. The publications have been focused on describing seal dynamics using either CFD [6-9] or bulkflow models [10,11], and they have shown that for seals under well-defined single phase flow conditions a reasonable match between theoretical and experimental results can be achieved [12], especially in the case of incompressible fluids [13]. Once a bulkflow model is built based upon several simplifying assumptions which do not necessarily hold [14] in practical industrial applications, several ways of "tuning" uncertain model parameters based on experimental as well as theoretical approaches can be explored [15].

To illustrate the challenges associated with the modeling of dynamic seal forces and the accurate prediction of seal force coefficients a survey was conducted in 2007. Here 20 survey participants from both industry and academia were asked to predict the dynamics of a gas labyrinth seal and consequently the rotordynamic behaviour [16]. The seals dynamics were predicted using bulkflow and CFD methods. 
zed the need for continuous efforts towards modeling and uncertainty handling of seal forces, even for single phase flow conditions.

Seal forces under multiphase flow conditions, i.e. where the fluid is an inhomogeneous mixture of gas and liquid, are still an open and difficult modeling task [17]. In this framework, larger model uncertainties should be expected for seals under multiphase flow conditions due to a limited knowledge about the dynamic behaviour of fluid forces under such conditions, especially when combined with complex seal geometries, such as hole-pattern and labyrinth. Model uncertainties are thus unavoidable due to the complexity of the fluid-structure interaction and the limitations of mathematical modeling associated with simplifying assumptions.

In AMB supported rotordynamic systems, the effect of gas seal destabilizing forces can be significantly mitigated by employing feedback controllers, if these controllers are properly designed and tuned. Designing and implementing feedback controllers for AMB supported rotordynamic systems that account for the destabilizing aerodynamic seal forces can be very challenging, due to i) the dependence of seal forces on the varying operating conditions such as rotational speed and pressure difference across the seal; ii) the changes in fluid (gas) properties; iii) changes in the process flow characteristics; and iv) model uncertainties. In this framework the necessity of designing robust controllers able to deal with uncertainties and parameter changes is clear. Several articles have focused on designing robust controllers for AMB systems [18-20]. A popular choice for designing robust Linear Time-Invariant (LTI) controllers for AMB systems is by using the $\mathcal{H}_{\infty}$ framework and a Linear Fractional Transformation (LFT) formulation to represent the nominal system and uncertainty. Using $\mathcal{H}_{\infty}$ with an uncertainty representation of the plant allows for the direct synthetisation of the controller, ensuring some worst-case performance guarantees. In many cases the conservativeness of the synthesised $\mathcal{H}_{\infty}$ controller can be reduced using DK-iteration, as done using the $\mu$ synthesis framework [21]. The robustness criteria for AMB systems are specified in ISO 14839-3 stating that the closed loop output sensitivity should be less than 3 for the system to be classified as Class A [22]. In the $\mathcal{H}_{\infty}$ framework such a requirement can be fulfilled by weighting the sensitivity function. Some articles report research efforts on fault-tolerant control methods. [18] shows that improved tolerance to specific external faults is achieved through $\mathcal{H}_{\infty}$ optimised disturbance rejection. Specifically, increased robustness is shown in the case of mass loss of rotor in a testrig with a flexible shaft and moveable baseframe. Improvement in performance of $\mathcal{H}_{\infty}$ controllers based on nonlinear plant compared to $\mathcal{H}_{\infty}$ controllers based on linear plant has been reported in [23]. In [19] the authors show that robust controllers for uncertain rotational speed can be addressed using an LFT consisting of the nominal system and a representation of how the system changes due to gyroscopic effects using gyroscopic matrix scaled by a repeated uncertainty. The natural frequencies of the flexible shafts bending modes are the main uncertainties treated in [20] and a robust controller is designed using $\mu$ synthesis. Robust stability to additive and multiplicative uncertainties can directly be ensured by applying complex weighting functions to the transfer functions KS (controller sensitivity) and T (complementary sensitivity). The conservativeness of the robust controller design can be reduced in the case of a Linear Parameter Varying (LPV) controller design, where one or more parameters are measured in real time, and can represent changing dynamics, which would otherwise be considered uncertain. A measured parameter could be the rotation speed, which can be utilized to reduce synchronous vibrations as shown in [24]. A flexible rotor subjected to uncertain Cross Coupled Stiffness (CCS) generated by using an extra set of active magnetic bearings previously been considered [25]. However, this demonstrated the difficulty in designing robust controllers using $\mu$ synthesis able to compensate for uncertain CCS in flexible rotating systems. Adaptive controllers to detect and compensate for cross coupling forces have been reported in [26] where the authors numerically simulated a rotordynamic system supported by AMB and subjected to a time variant CCS. An observer was built and theoretically demonstrated the ability to track the changes of CSS parameter in time. Using pole placement techniques a controller was designed to work along with the observer. In [27] the authors estimated on-line the unknown CSS parameter of a rotor by a recursive least square estimator. Simulation results of adaptive control in parallel with a baseline PID controller were considered in [28], where the controller was designed to compensate for changes of CCS in time and periodic disturbance forces. The work shows that the adaptive controller could handle much larger amplitudes of CCS forces than a fixed LTI Linear-Quadratic Regulator (LQR). However, to date, only numerical studies have been carried out dealing with the adaptive controller problem. In general stability and robustness are hard to guarantee in adaptive control systems which is crucial for implementation in industrial applications.

The design and simulated results using $\mathcal{H}_{\infty}, \mu$ and LPV controllers to compensate for uncertain and varying seal forces in a turbocharger supported by AMBs are demonstrated in [29]. Specifically, a hole pattern seal is considered for a balance piston in a turbo-expander application. Performance improvements are shown when using robust control for handling model uncertainties in the dynamic force coefficients of the seal, compared to a controller based on a nominal model. Also, since the dynamic seal coefficients of the hole pattern seal are heavily dependent on the excitation frequency, an LPV controller is designed to deal with the frequency dependency using the rotational speed as the scheduling parameter. The performance enhancements compared to a $\mu$ controller are shown for delivering performance over the complete rotational speed range.

A method for identification of uncertain/unknown seal and electromechanical parameters, to obtain a precise global model of an AMB-rotor-seal test facility is presented in [30]. The test facility is described in [31]. The method can be employed on-site without the use of any calibrated force measurement sensors - only the free-free model of the shaft is 


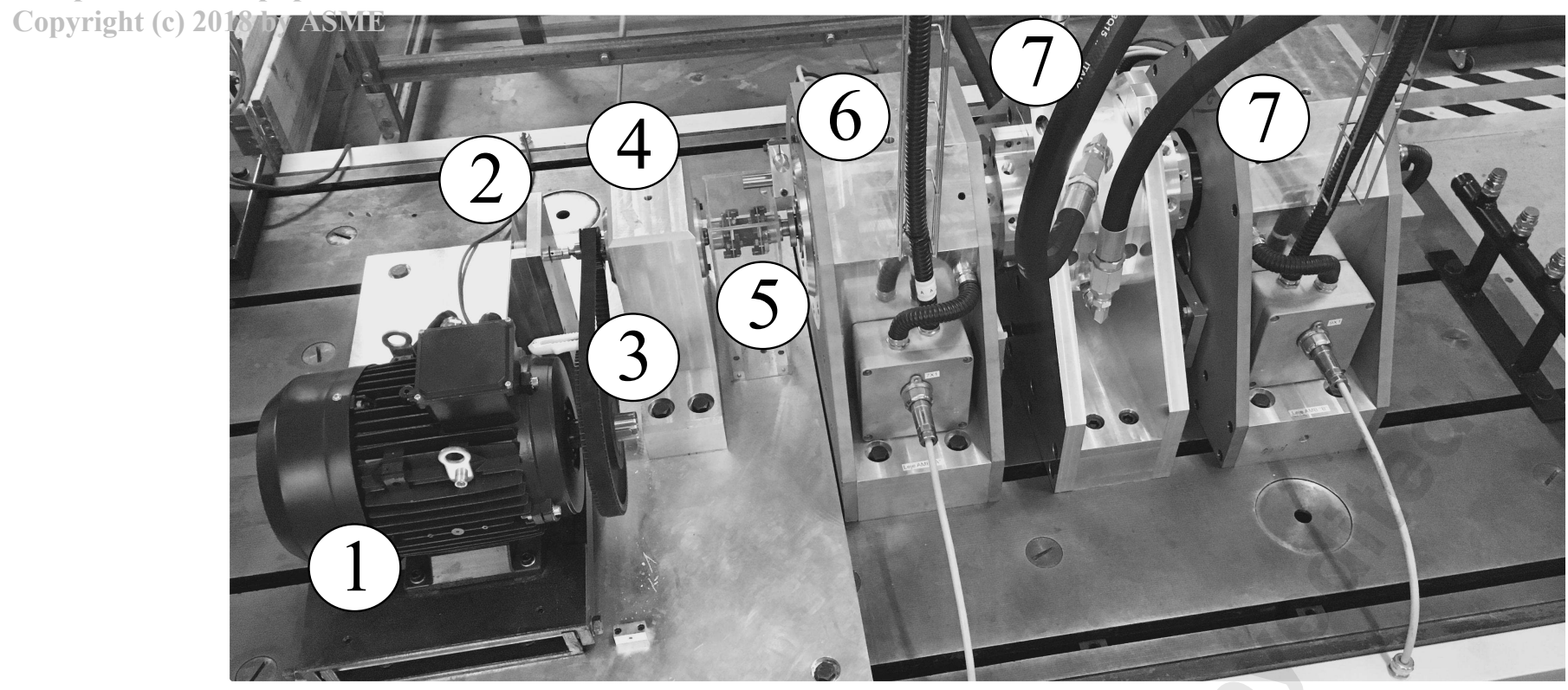

Fig. 1: Test facility overview. (1) motor, (2) Encoder, (3) Belt drive, (4), Intermediate shaft pedestal, (5) Flexible coupling. (6) AMB A, (7) Seal housing, 8 AMB B.

needed a-priori. The seal forces are characterized as direct stiffness and damping coefficients and cross coupled stiffness and damping coefficients which are functions of pressure across the seal and excitation frequency. This method could potentially be implemented in all rotor dynamic systems supported by AMBs and subjected to seal forces.

This paper uses the rotor dynamic model with in-situ identified seal coefficients, presented in [30], to design model based controllers, for handling dynamic seal forces. The idea is to enhance the performance of the global system without increasing the direct stiffness or damping of the system. In this study the rotor is non-rotating.

This paper is structured as follows. In Section 2, a description of the AMB-rotor-seal test facility is provided. In section 3, a mathematical model representation of the nominal and perturbed plant is given, followed by the results of the global model with identified seal coefficients. In Section 4, the controller design structure and weight function selection is presented. In Section 5, the simulated and experimental results of a PID reference controller and the synthesised $\mathcal{H}_{\infty}$ and $\mu$ controllers for handling seal forces at different pressures is demonstrated.

\section{Experimental Facility}

The experimental facilities used for this work consist of an AMB-based rotordynamic test bench with a seal housing presented in Fig. 1. Two AMBs radially support a symmetric rigid rotor which is driven by an asynchronous motor through an intermediate shaft and a flexible coupling, as seen in Fig. 1. Angular contact ball bearings, supporting the intermediate shaft housed in the intermediate shaft pedestal, compensate for axial forces acting on the rotor. The radial AMBs are of the eight pole heteropolar type.

The global reference frame is denoted by $x, y$ and the actuator reference frame is denoted by $\zeta, \eta$, which is tilted $45^{\circ}$ with respects to the global reference frame. The two AMB stators have been manufactured using two different production methods yielding different geometric tolerances for the AMBs. The AMBs are supplied by four $3 \mathrm{~kW}$ laboratory amplifiers.

The seal, mounted in the center of the shaft, is installed as a back-to-back configuration, hence two symmetrical seals are placed to cancel out possible axial fluid film forces. It is designed with primary and secondary discharge seals to avoid any liquid entering the AMBs, since the test facility is designed to operate with both gas, liquid and mixtures between gas and liquid. The fluid used in this article is gas, though. The fluid is injected by four highly angled nozzles to obtain a high preswirl ratio, hence the fluid is already rotated at the inlet of the seal. A cross section of the injection system is shown in Fig. 2.

A full description of the test facility can be found in [32] and the design parameters for the rotor dynamic test bench can be found in Table 1 .

Table 1: Design parameters for the rotordynamic test bench

\begin{tabular}{lrl}
\hline Rotor length & 860 & $\mathrm{~mm}$ \\
Rotor assembly mass & 69 & $\mathrm{~kg}$ \\
1st rotor bending mode @ & 550 & $\mathrm{~Hz}$ \\
Stator inner diameter & 151 & $\mathrm{~mm}$ \\
Nominal radial air gap & 0.5 & $\mathrm{~mm}$ \\
Number of windings & 36 & {$[-]$} \\
\hline
\end{tabular}




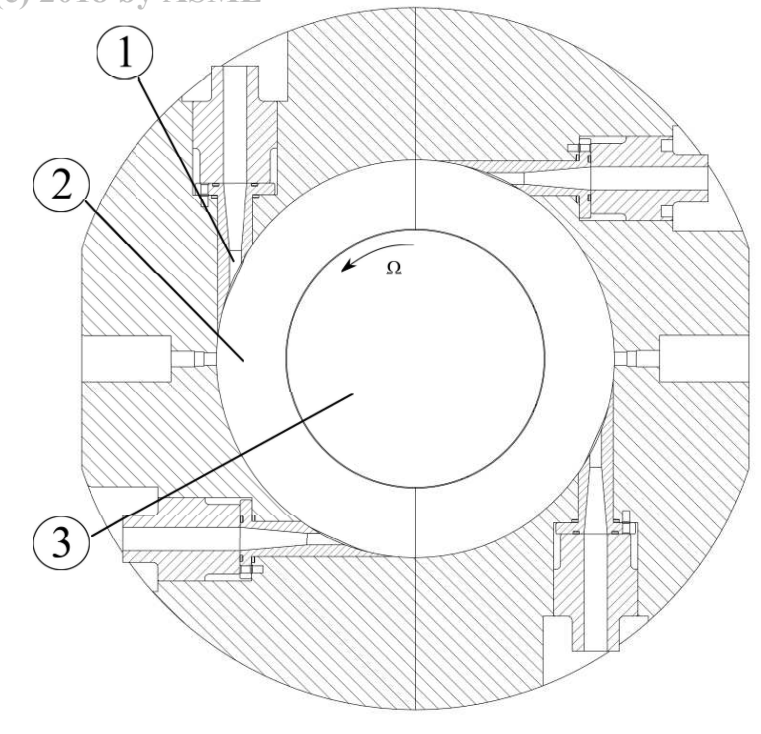

Fig. 2: Cross section of the seal house at the inlet cavity section. (1) inlet injection nozzle, (2) inlet cavity, (3) shaft. The figure is adapted from [31]

\section{Mathematical Modeling, Perturbed Plant and System Identification}

This section presents details about the mathematical system, the perturbed system representation and the results of system identification - all related to the models used for control synthesis. The modeling and identification of uncertain/unknown parameters of the test facility are described in detail in [30].

\subsection{Mathematical Model}

The global mathematical model describes the dynamic interaction among all test-rig components, namely rotor, AMB, motor-shaft flexible coupling and gas seal. An overview of the forces acting on the rotor and sensor positions is given in Fig. 3

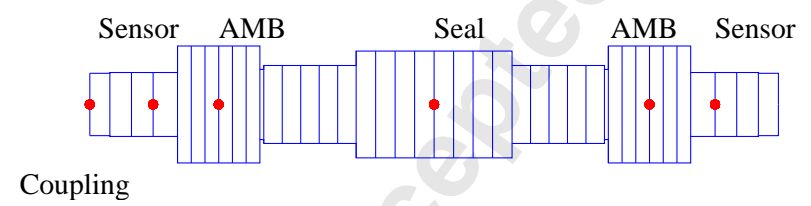

Fig. 3: Overview of the forces acting on the rotor and sensor positions. The red dots marks the input/output locations. The blue lines shows the finite elements of the shaft model.

\subsubsection{Model of AMB Forces}

The model of the magnetic bearing is simplified to describe the forces acting on the rotor as function of the rotor lateral displacements at the AMB location $s_{x}$ and the control current $i_{x}$. The linearised expression of the forces is given as [33]

$$
f_{b}\left(i_{x}, s_{x}\right)=K_{i} i_{x}+K_{s} s_{x}
$$

where $K_{i}$ are $K_{s}$ are constants. Initial estimates of $K_{i}$ and $K_{s}$ have been obtained using first principle methods and identified as shown in [30]. The dynamics of the electromechanical system, including the inductance of the coil and the amplifiers, is approximated using a second order model, denoted $G_{a c t}$

$$
G_{a c t}=\frac{\omega_{n}^{2}}{s^{2}+\xi \omega_{n} s+\omega_{n}}
$$

where the damping coefficient and natural frequency are found to be $\xi=0.9$ and $\omega_{n}=1360 \mathrm{rad} / \mathrm{s}(216 \mathrm{~Hz})$.

\subsubsection{Model of Dynamic Seal Forces}

The dynamic seal forces are commonly described by their linearised force coefficients: stiffness, damping and sometimes mass matrices. Mass coefficients are hereby neglected since the fluid used is air [34]

$$
\left[\begin{array}{l}
f_{\zeta} \\
f_{\eta}
\end{array}\right]=\left[\begin{array}{cc}
K & k \\
-k & K
\end{array}\right]\left[\begin{array}{l}
\zeta \\
\eta
\end{array}\right]+\left[\begin{array}{cc}
C & c \\
-c & C
\end{array}\right]\left[\begin{array}{l}
\dot{\zeta} \\
\dot{\eta}
\end{array}\right]
$$

This model has a symmetric structure since the shaft is assumed to be in the center of the seal. The coefficients are generally a function of the rotational speed and the excitation frequency.

\subsubsection{Model of Flexible Coupling Forces}

The force of the flexible coupling is modeled using linear stiffness associated with the lateral movements of the shaft. Angular stiffness associated with the tilting movements of the shaft is considered negligible, leading to:

$$
\left[\begin{array}{l}
f_{\zeta} \\
f_{\eta}
\end{array}\right]=\left[\begin{array}{cc}
K_{c_{\zeta}} & 0 \\
0 & K_{c_{\eta}}
\end{array}\right]\left[\begin{array}{l}
\zeta \\
\eta
\end{array}\right]
$$

The stiffness matrix has been identified by shaking the rotor using the AMBs as shown in [30].

\subsubsection{Model of Shaft}

The dynamic behaviour of the rotating shaft is mathematically described using the Finite Element (FE) method and Bernoulli-Euler beam theory considering the gyroscopic effects of the shaft and discs [35]. The shaft model is built using 40 node points with 4 degrees of freedom each, i.e. $x$ and $y$ direction, and the rotation around the $x$ and $y$ axes. It yields 320 states in total. The global rotordynamic system 
nearised AMB force coefficients $K_{i}$ and $K_{s}$, the stiffness and damping of the seal and the stiffness of the coupling can be written in state space form. Using modal truncation techniques, real left and right modal transformation matrices are obtained which transform the full order FE system to a reduced form. The first bending mode frequency lies at $550 \mathrm{~Hz}$ and the shaft is considered rigid for the work carried out in this paper. Thus, all bending modes have thus been removed in the reduced order model. The FE model is selected though for generality and for possibility of extending the model to include some of the bending modes if needed. The rotational speed is kept at zero for this study to isolate the seal effects. The tangential fluid flow is induced by means of four injectors built as illustrated in Fig. 2, what leads to high preswhirl effect. The state space matrices representing the nominal rotor dynamic system, $A, B$ and $C$ are given in Appendix A. These system matrices are normalised using scaling constants for simpler weight function selection in the control design, $D_{e}^{-1} G_{f} D_{u}$, using $D_{e}=20 \times 10^{-6} \mathrm{~m}$ indicating the largest allowed control error and $D_{u}=1 \mathrm{~A}$ indicating the maximum allowed input change.

\subsection{Perturbed Plant Representation}

The nominal model can be extended to include changes or uncertainties in the plant dynamics. This is utilized for identification of uncertain AMB parameters $K_{i}, K_{s}$ as well as unknown seal parameters $K, k, D, d$, as described in [30]. In this paper, Section 4 , the perturbed system representation is utilised for the design of robust controllers. The perturbed plant $G_{f i}$ is constructed using the nominal model ( $A$, $B$ and $C$ ) and the uncertain dynamics representation, which are combined and written in LFT form, as illustrated in Fig. 4 [36]. Here $\Delta$ is a diagonal matrix representing the uncer-

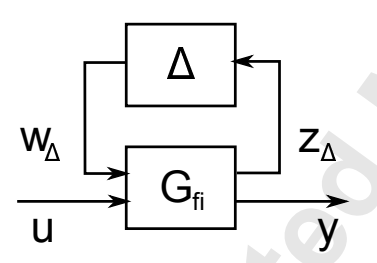

Fig. 4: Updated/changed plant representation using upper LFT, $G_{\text {updated }}=\mathcal{F}_{u}\left(G_{f i}, \Delta\right)$

tain parameters to be identified. $G_{f i}$ can be written in state space form, as shown in Eq. (5), where A, B and C are the nominal system matrices. Here the input and output matrices are extended from the nominal model to include the input and output mapping $B_{\Delta}$ and $C_{\Delta}$.

$$
G_{f i}=\left[\begin{array}{c|cc}
A & B_{\Delta} & B \\
\hline C_{\Delta} & 0 & 0 \\
C & 0 & 0
\end{array}\right]
$$

$B_{\Delta}$ and $C_{\Delta}$ represent changes in the nominal plant caused by deviations in stiffness and damping of the gas seal. $B_{\Delta}$ and $C_{\Delta}$ are built as shown in $[29,30]$ and given in Appendix A.

\subsection{Identification of Seal Parameters for Different Pres- sures}

The seal force parameters of the specific test seal have been identified in [30]. Here the seal coefficients are identified using sinusoidal disturbance forces at different frequencies to investigate their frequency dependency. The excitation force is generated using the AMBs by adding an excitation current on top of the control current used to stabilize and levitate the rotor. From the experiments, it is seen that the seal adds a significant amount of cross coupled stiffness which is dependent on the applied pressure and that the seal force coefficients have no frequency dependency in the frequency range of $0-200 \mathrm{~Hz}$. Since the seal force coefficients are considered frequency independent and the stepped sinusoidal procedure is time-consuming, it is chosen to identify the seal force parameters for different pressures using impulse disturbances of $0.05 \mathrm{~A}$ with a duration of $10 \mathrm{~ms}$ for both bearings in $\zeta$ direction. Impulse responses showing the performance of the identified global model compared to experimental data are seen in Fig. 5 and 6, where the seal force coefficients have been identified at pressures of 0.95 bar and 1.90 bar, respectively. The decentralised PID controller with the gains given in Sec. 4.2 is used for the identification of the seal forces. The simulated and experimental responses match very well, indicating that the model captures the seal dynamics well. Moreover, the shaft lateral displacements at $A_{\zeta}$ are smaller than at $B_{\zeta}$ due to the coupling montage near bearing $\mathrm{A}$ and due to different $K_{i}$ and $K_{s}$ values of the two bearings. Identification results of $K_{i}$ and $K_{s}$ values can be found in [37] and coupling stiffness values can be found in [30]. Shaft lateral displacements are also detected in $\eta$ direction due to the cross coupling gas seal forces. Nevertheless, the shaft lateral response in $\eta$ direction is relatively low due to the low values of pressure drop along the seals, as depicted in Fig. 5 for pressure drops of 0.95 bar. The shaft lateral response in $\eta$ direction becomes significantly larger when the pressure drop across the seal is increased by a factor 2 , namely to 1.90 bar, as illustrated in Fig. 6.

The behaviour of the identified seal force coefficients as a function of the pressure drop along the seal is shown in Fig. 7. Linear regression lines are shown to highlight the trends and the estimation uncertainty of each coefficient. The direct stiffness $K$ is low and weakly-dependent on the pressure drop along the (worn) seal with relatively large radial clearance. The cross coupled stiffness $k$ is the most significant parameter and has a strong correlation with the applied pressure. It can be observed in Fig. 7 that the uncertainty of the estimated damping parameters, relative to their size, is large; though, it is normally expected that there is larger uncertainties in estimating damping than stiffness parameters. As shown in [30] direct damping $D$ improves the global models accuracy. Nevertheless, such an identified parameter seems to compensate for some residual dynamics coming from the 
Copyright eilectro dynamics rather than from the gas seal. The cross coupled damping decreases with increased pressure drop along the gas seal in the pressure range investigated.

Fig. 7 also shows the nominal pressure for the control design. Nominal gas seal force coefficients are found at the pressure of 2.15 bar using the values obtained from the linear regression lines.

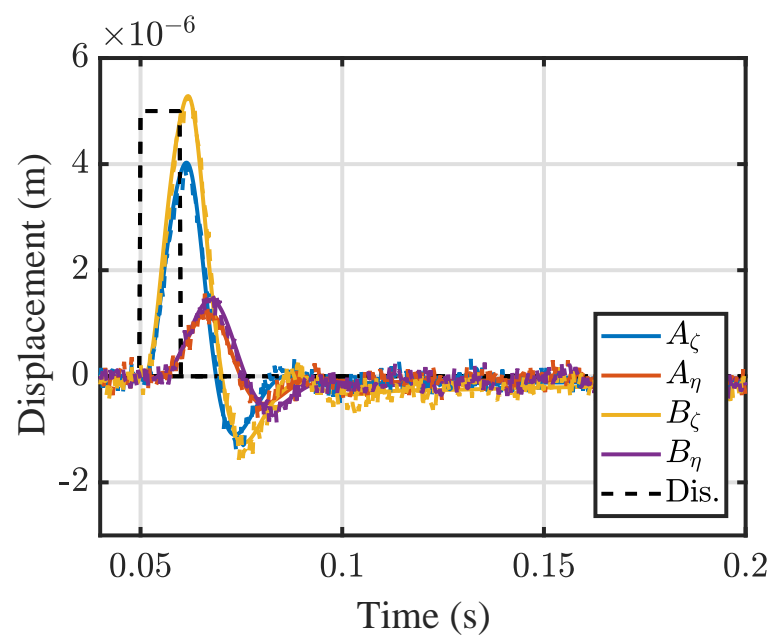

Fig. 5: Comparison of experimental (solid lines) and global model (dashed) impulse response using 0.95 bar inlet pressure. The global model includes the seal coefficients identified for the given pressure. Current impulse disturbance from $0.05 \mathrm{~s}$ to $0.06 \mathrm{~s}$ is scaled in amplitude and shown as the dashed line.

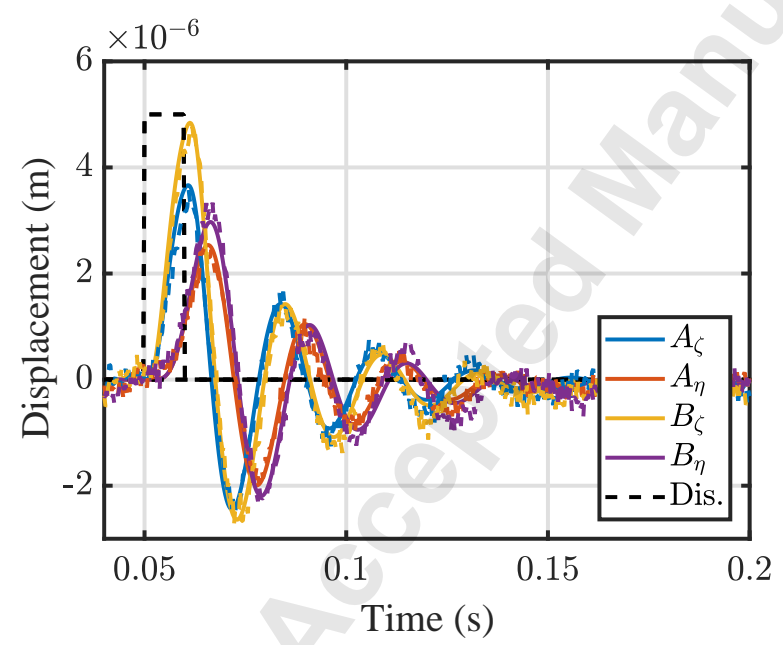

Fig. 6: Comparison of experimental (solid lines) and global model (dashed) impulse response using $1.90 \mathrm{bar}$ inlet pressure. The global model includes the seal coefficients identified for the given pressure. Current disturbance from $0.05 \mathrm{~s}$ to $0.06 \mathrm{~s}$ is scaled in amplitude and shown as the dashed line.

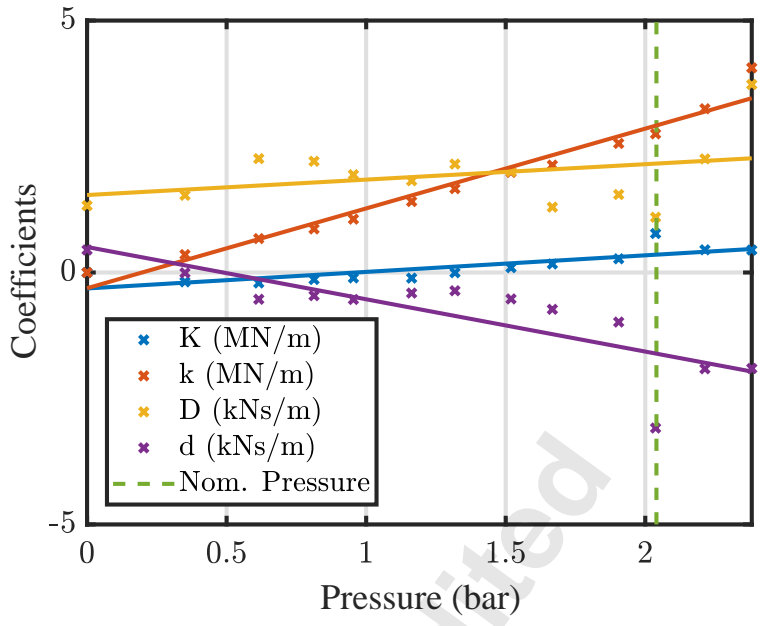

Fig. 7: Seal coefficients as function of the pressure drop across the seal inlet marked with ' $x$ '. The solid lines show linear regression lines, estimated for each coefficient. The nominal pressure, used for the design of the model based controllers, is shown as the dashed line.

\section{Design of Controllers}

\subsection{Control Design Objectives and Challenges}

An $\mathcal{H}_{\infty}$ controller and $\mu$ controller are designed with the following objectives

1. The synthesised controllers should have similar gains of the direct terms in the frequency range of $0-200 \mathrm{~Hz}$ for them to be comparable. It is less challenging to find a controller that robustly stabilizes the plant for uncertain seal forces if the direct stiffness and damping gains are proportionally much higher than the cross coupled forces from the seals. Especially for the specific case where the rotor is considered rigid and thus no flexible modes will be excited.

2. Due to changes of the operational pressure across the seal, the controllers should deliver robust performance to plants with pressure drop changes within $\pm 100 \%$ of the nominal pressure drop across the seal. The nominal pressure drop is chosen to be 2.04 bar, i.e. the controller must deliver robust performance in the range of 0 4.08 bar. Due to high preswhirl flow conditions associated to the gas seal under investigation, it is assumed that pressure changes only significantly alter the cross coupled stiffness $k$. Thus, changes in the seal coefficients $K$, $D, d$ due to pressure change have been neglected when synthesizing the controllers and evaluating the compliance and sensitivity functions. It should however be noted that the nominal values of the coefficients are used in the nominal model. The identified values of $K, D$ and $d$ for two given pressures drop scenarios are directly used in the experimental validation of the controllers in Sec. 5.2 to show the exact controller performance.

3. The same parametric uncertainty $\delta_{1}$ is used both for $k$, $-k$ to reduce the conservativeness in regard to synthesizing the robust controllers (See Appendix A).

4. The controller should satisfy ISO 14839-3, which sta- 
should be less than 3 for all frequencies in order to be classified as Zone A [22]. This is to ensure a general robustness of the system due to unmodelled dynamics and gains in the system which can change over time. Although ISO 14839-3 only requires the sensitivity to be lower than 3 for each diagonal element, it is in this framework required that the maximum singular value of the full sensitivity function to be lower than 3 to ensure robustness due to cross coupled dynamics.

5. The compliance function should be as low as possible over the complete operational range to ensure small orbits and responses due to unbalance forces and other external disturbances.

\subsection{Reference controller}

A decentralised PID controller is chosen as a reference controller with an integral time $T_{i}$ of $0.2 \mathrm{~s}$ and derivative time $T_{d}$ of $3.5 \mathrm{~ms}$ with the transfer function

$$
K_{P I D}=K_{p}\left(1+\frac{1}{T_{i} s}+\frac{T_{d} s}{\varepsilon T_{d} s+1}\right)
$$

The derivative action is limited for high frequencies using the term $\varepsilon T_{d} s+1$ with $\varepsilon=0.1 . K_{p}$ is the overall gain of the controller. This type of controller is the most commonly used controller in the industry for AMB systems due to its simple structure with only a few parameters to be tuned. This controller has shown to deliver good performance during an extensive experimental testing campaign. Nevertheless, due to its decentralised structure, it does not directly compensate for lateral cross coupling interaction coming from gyroscopic or seal forces.

\subsection{Robust Control Design Interconnection and Weight Functions}

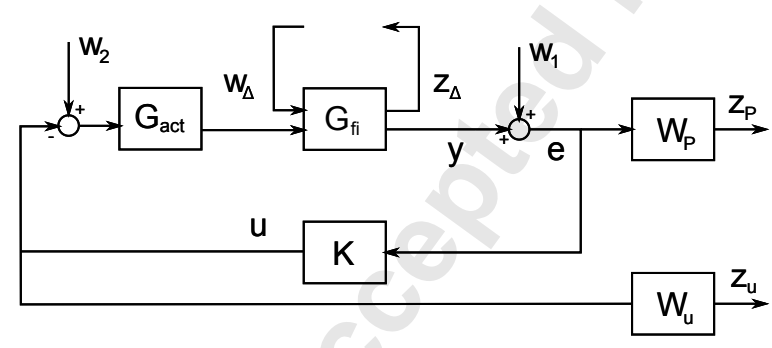

Fig. 8: Interconnection of actuator model $G_{a c t}$, rotordynamic model with uncertainty representation $G_{f i}$, performance weight functions $W_{P}$ and $W_{u}$, and controller $\mathrm{K}$.

The interconnection in Fig. 8 and 9 is used for robust controller synthesis. $W_{p}$ shapes the sensitivity functions i.e. the relationship from input and output disturbances $W_{1}$ and $W_{2}$ to the displacement error $e$. $W_{p}$ is formulated with the

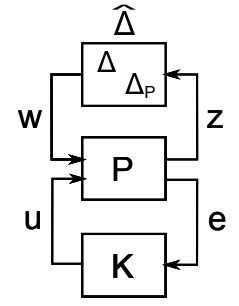

Fig. 9: Interconnection rearranged to the augmented system $\mathrm{P}$, externally connected to the controller and $\hat{\Delta}$ containing $\Delta$ for uncertain plant representation and $\Delta_{P}$ as full complex perturbation for performance specification.

structure

$$
W_{p}=\frac{\frac{s}{M}+w_{B}}{s+w_{B} A_{w}}
$$

The weighting function $W_{p}$ has multiple purposes: I) Set a low sensitivity at low frequencies to obtain an integral effect, which eliminates steady state error in position reference. The constant $A_{w}$ indicates the steady state error and is set to $\frac{1}{1000}$. II) The constant $M$ indicates the maximum peak of the sensitivity functions and is tuned to obtain a peak value smaller than 3 (or $9.5 \mathrm{~dB}$ ) for robustness [22]. III) The crossover frequency $w_{B}$ indicates the desired bandwidth of the closed loop system [36]. This parameter is tuned to achieve an integral time close to the reference controller of $0.2 \mathrm{~s}$.

The weight $W_{u}$ has a function of adjusting the roll-off frequency of the controller and the amount of control effort. This weight is tuned to obtain similar gains as the PID reference controller in the mid range frequency range. The weight $W_{u}$ is chosen as a constant and is independently tuned for the synthesis of the $\mathcal{H}_{\infty}$ and $\mu$ controllers to obtain similar gains of the direct terms, in order words, $K_{\mathcal{H}_{\infty}}(1,1) \approx$ $K_{\mu}(1,1), K_{\mathcal{H}_{\infty}}(2,2) \approx K_{\mu}(2,2), K_{\mathcal{H}_{\infty}}(3,3) \approx K_{\mu}(3,3)$ and $K_{\mathcal{H}_{\infty}}(4,4) \approx K_{\mu}(4,4)$ as shown in Fig. 10.

\subsection{Robust Control Synthesis}

Fig. 8 shows the interconnection rearranged for controller synthesis such that $\mathrm{P}$ is the fixed augmented plant. Note that $\Delta$ is for the uncertain plant representation and $\Delta_{P}$ (full perturbation matrix representing the $\mathcal{H}_{\infty}$ performance specification) are collected into the diagonal elements of $\hat{\Delta}$. Hence synthesising a controller can be done by finding a controller that minimises the $\infty$ norm of the transfer function from $w$ to $\mathrm{z}$, formulated as a lower LFT

$$
\gamma=\left\|F_{l}(P, K)\right\|_{\infty}
$$

An $\mathcal{H}_{\infty}$ controller of order 20 is synthesized using the nominal plant representation and a $\mu$ controller of order 24 is synthesized using the perturbed plant. The state space matrices of the synthesised controllers can be found in Appendix B. The gain of the controller transfer functions is shown in 
Copyright fig. ${ }^{20} 10$. The shape of the direct terms of both the $\mathcal{H}_{\infty}$ - and $\mu$ controller turns out to be very similar to the PID controller. While the direct gains of the three controllers are similar (up to $200 \mathrm{~Hz}$ ), some of the cross coupling gains are quite different for the $\mathcal{H}_{\infty}$ and the $\mu$ controller, as shown for the term(1,3), representing the coupling between $A_{\zeta}$ and $B_{\eta}$, i.e. cross coupling gain linking the lateral movements of the shaft at bearing locations A and B in their orthogonal directions $\zeta$ and $\eta$ (centralized controller).

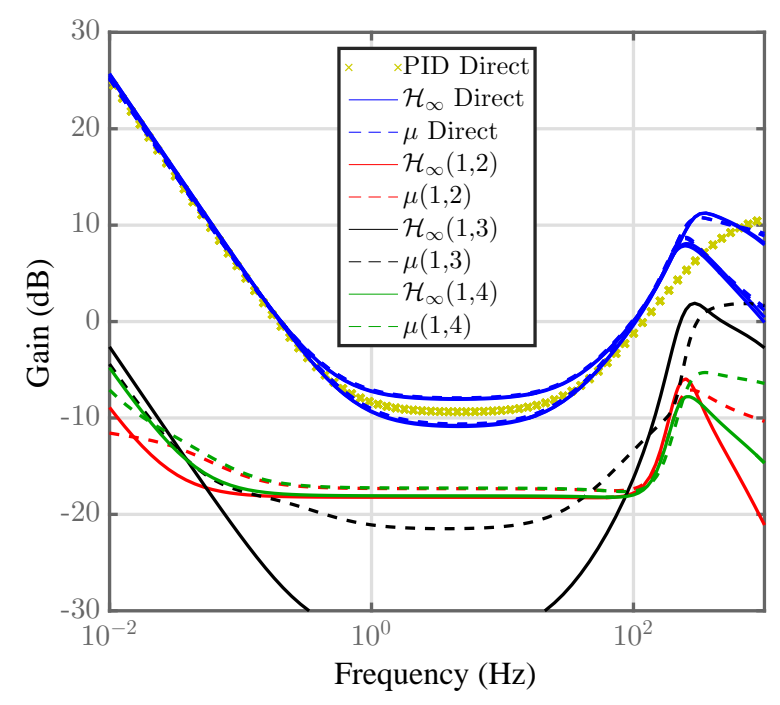

Fig. 10: Comparison of the direct and cross coupled gain of the controllers. Indices $[1,2,3,4]$ represent node points $\left[A_{\zeta}\right.$, $\left.A_{\eta}, B_{\zeta}, B_{\eta}\right]$

\subsubsection{Compliance Function}

The compliance transfer function describes the relation between rotor lateral displacements at bearing locations A and $\mathrm{B}$ and external perturbation forces. This function must be as low as possible at all frequencies to ensure good force disturbance rejections and small orbits. An upper bound of the amplitude of the compliance function can be found by calculating maximum singular values of the compliance function, $\bar{\sigma}\left(G_{f}\right)$. These are shown for the system at nominal pressure (solid lines) and at nominal pressure with $\pm 100 \%$ variation of nominal pressure in Fig. 11.

Not surprisingly, it is seen that $\mathcal{H}_{\infty}$ and $\mu$ controllers have their lowest amplitude over the frequency range for the nominal pressure (solid lines), since this corresponds to their design point, i.e. nominal operational pressure across the seal of 2.15 bar. Their amplitudes for the nominal pressure are only slightly higher than for the PID controller at low pressure condition. The rotor-bearing-seal system operating with the PID controller has a resonance peak at $40 \mathrm{~Hz}$ at nominal pressure. At a slightly higher frequency $(50 \mathrm{~Hz})$ the $\mathcal{H}_{\infty}$ has a peak which is the largest for the low pressure condition. Rotor-bearing-seal system operating with both the $\mathcal{H}_{\infty}$ and $\mu$ controllers have a resonance peak at a low frequency at ap-

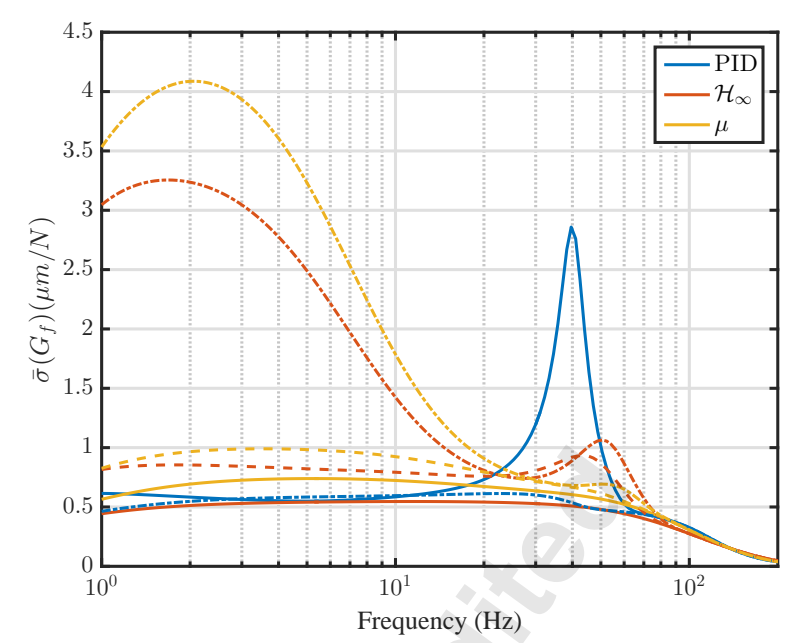

Fig. 11: The maximum amplitude of the compliance function using the three controllers. The solid lines indicate the performance of the controllers at nominal pressure. The lines marked with '- -' indicate high pressure i.e. $+100 \%$ of pressure compared to the nominal pressure and the lines marked with '-.' indicate low pressure i.e. $-100 \%$ of pressure compared to the nominal pressure. The PID controller with high pressure is not shown since this makes the system unstable.

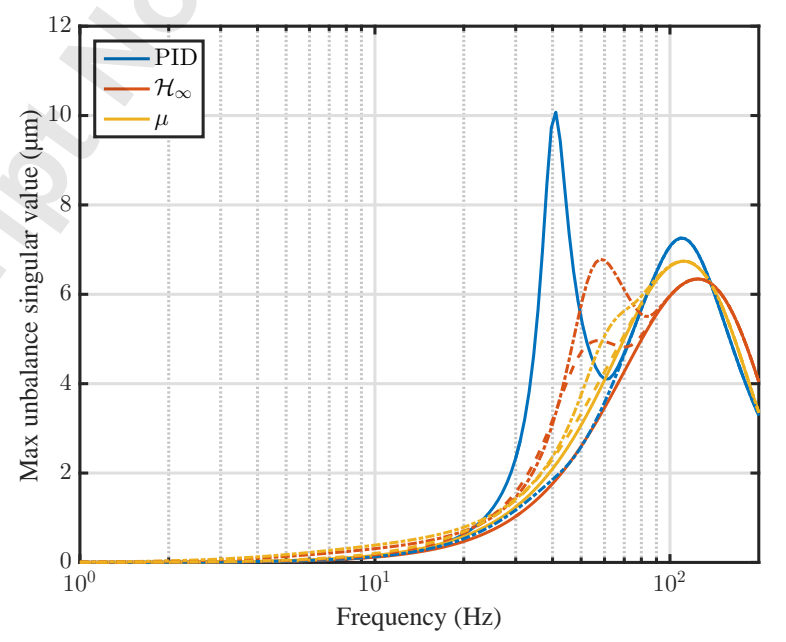

Fig. 12: The maximum singular value of the unbalance function for the three controllers. The solid lines indicate the performance of the controllers at nominal pressure. The lines marked with '- -' indicate high pressure i.e. $+100 \%$ of pressure compared to the nominal pressure and the lines marked with '-.' indicate low pressure i.e. $-100 \%$ of pressure compared to the nominal pressure. The PID controller with high pressure is not shown since this makes the system unstable.

proximately $2 \mathrm{~Hz}$ for low pressure conditions, showing their worst performance at low frequencies. This is evidenced by the highest compliance values at low frequencies in Fig. 11. The compliance function can be used as an indication of the worst case of unbalance response, if this function is multiplied by expected unbalance force, as shown in Fig. 12. 
Copyright Assuming the shaft is balanced according to the G2.5 norm at $500 \mathrm{~Hz}$ results in a maximum unbalance force of $541 \mathrm{~N}$ at $500 \mathrm{~Hz}$. Both the $\mathcal{H}_{\infty}$ and $\mu$ controllers ensure an orbit below $8 \mu \mathrm{m}$ over the $200 \mathrm{~Hz}$ frequency range, which is considered acceptable. Gyroscopic effects are neglected for simplicity.

\subsubsection{Sensitivity of Perturbed Plant Using Different Controllers}

The closed-loop output sensitivity functions are shown in Fig. 13 using the perturbed plant with $\pm 100 \%$ cross coupled stiffness variation and the PID, $\mathcal{H}_{\infty}$ and $\mu$ controllers. The $\mu$ controller nearly ensures the maximum peak of the singular values of the closed loop sensitivity function to be below 3 (or $9.5 \mathrm{~dB}$ ), as recommended by ISO 14839-3. The $\mathcal{H}_{\infty}$ has higher sensitivity peaks than 3 , but stabilises the plant for the whole pressure range. The PID controller has very high peaks and does not stabilise the system for high pressures. The input sensitivity is seen to be very similar to the output sensitivity and is not shown here.

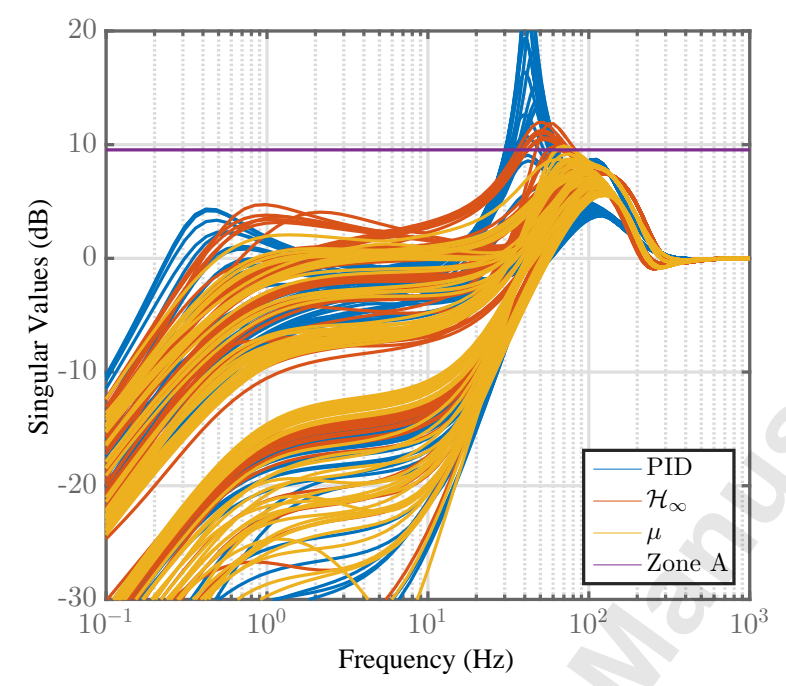

Fig. 13: Closed-loop output sensitivity of perturbed plant using PID, $\mathcal{H}_{\infty}$ and $\mu$ controllers.

\section{Theoretical and Experimental Results}

The performance of the designed controllers is demonstrated in this section using different disturbances and pressures. Simulation results show the performance of the perturbed plant in terms of the rotor lateral displacement and AMB current responses to current impulse disturbances. Experimental verification of the closed loop performance under different pressure conditions is shown for a pressure and a no pressure condition with two different current impulse disturbances.

\subsection{Time Simulation of Perturbed Plant Operating With Different Controllers}

Fig. 14 shows the simulated impulse response of the perturbed plant. Identical impulsive $10 \mathrm{~ms}$ disturbances of $0.05 \mathrm{~A}$ on both $\mathrm{AMBs}$ are simultaneously applied, exciting the rotor lateral movements orthogonally at positions $\mathrm{A}$ and B, i.e. directions $A_{\zeta}$ and $B_{\eta}$. There is a clear coincidence between the robustness issues in terms of the high peaks in sensitivity functions shown in Fig. 13 and the oscillations in the responses shown in 14 . The $\mu$ controller leads to a rotor-bearing-seal system with lower sensitivity peaks and more stable (shorter settling time) than the system with the $\mathcal{H}_{\infty}$ controller. The rotor-bearing-seal system with PID controller turns unstable for high pressures across the gas seal. It is interesting to note that the $\mu$ controller handles the cross coupled forces differently to the $\mathcal{H}_{\infty}$ controller seen at the beginning of the impulse response. Here it can be seen that the two controllers requested currents start in opposite directions at $A_{\eta}$.

\subsection{Experimental Validation of Controller Performance}

The controller performance due to the impulse excitation current is verified experimentally, using a current disturbance simultaneously at the orthogonal directions and different bearing locations $A_{\zeta}$ and $B_{\eta}$, as shown in Fig. 15, and using a current disturbance simultaneously at the different bearing locations but in one single direction $\zeta, A_{\zeta}$ and $B_{\zeta}$, as shown in Fig. 16. It is chosen to benchmark the controllers at two conditions: 1) at a pressure drop of 2.04 bar which is the nominal design condition of the model based controllers. 2) at zero pressure drop which corresponds to a deviation of the cross coupled stiffness of $-100 \%$ compared to the nominal design condition of the model based controllers. This is to test the robust performance of the model based controllers, i.e. how well they perform when operating far away from the nominal conditions. It is also to see the performance of the PID controller and how well the model performs, when applying different controllers. Fig. 15a, b, c and Fig. 16a, $\mathrm{b}, \mathrm{c}$ show the rotor lateral displacement responses for zero pressure drop across the gas seal while Fig. 15d, e, f and Fig. $16 \mathrm{~d}, \mathrm{e}, \mathrm{f}$ show the responses for the case of 2.04 bar across the gas seal. The experimental and simulated responses match well, indicating that the model fits well for different disturbances and the controllers act as expected. The seal force coefficients are identified based on responses using the PID reference controller as described ealier. From the plots, it can be observed that

1. The decentralized PID shows good performance when no pressure is applied as seen in e.g. Fig. 15a. The displacement in $A_{\zeta}$ and $B_{\eta}$ directions are not equal despite the same sized current disturbance being applied in both AMBs. This is due to the flexible coupling that is mounted close to bearing $A$, and due to bearing $A$ and $B$ having different $K_{i}$ and $K_{s}$ values. No cross coupling is seen in the responses for the disturbance entering via $A_{\zeta}$ and $B_{\zeta}$ since no pressure is applied and no significant cross coupling exists in the decentralised PID controller. This is 


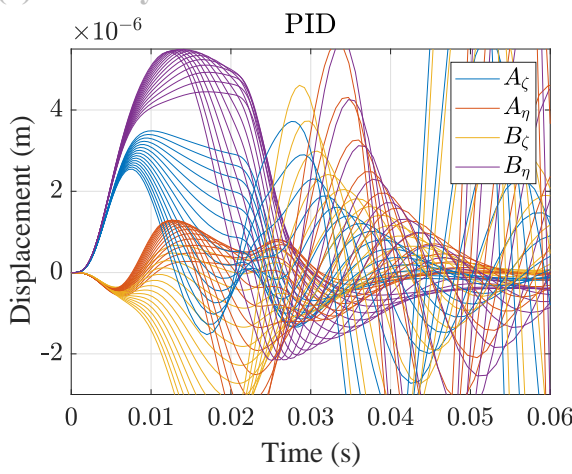

(a)

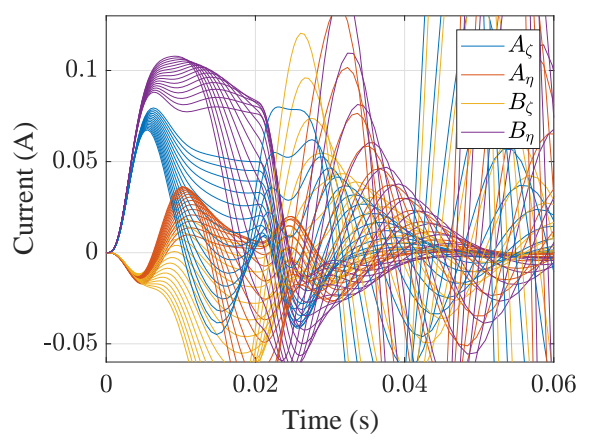

(d)

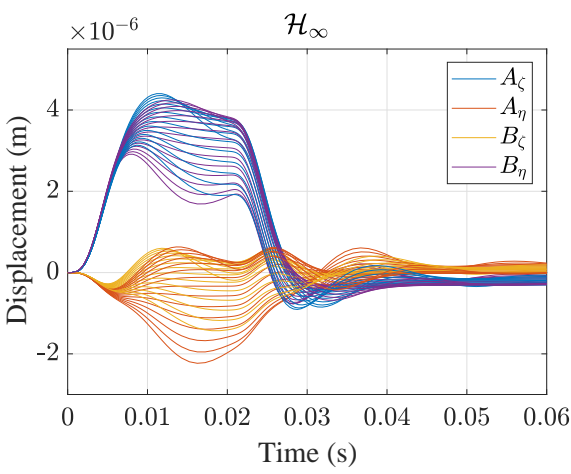

(b)

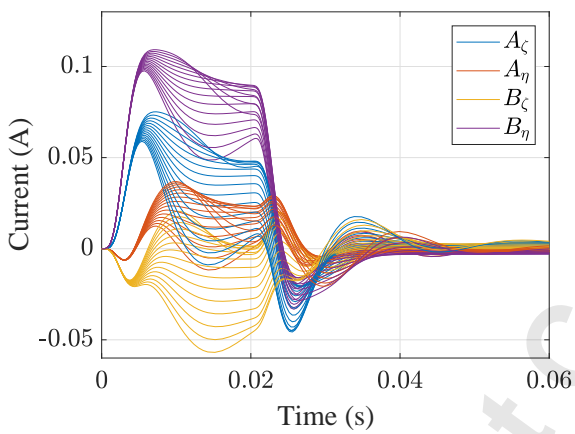

(e)

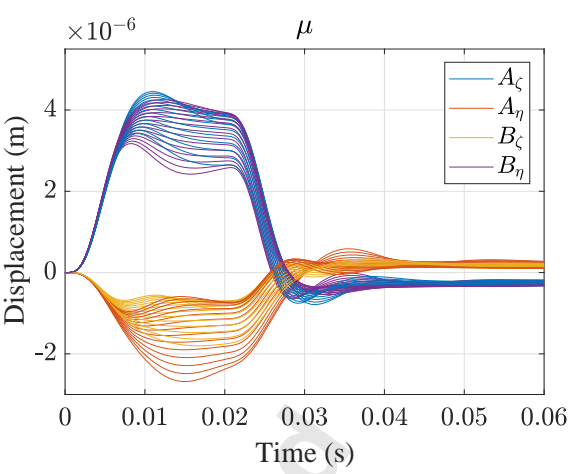

(c)

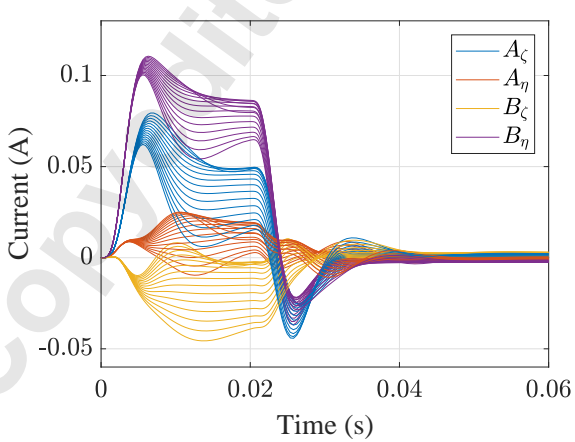

(f)

Fig. 14: Impulse response of perturbed plant: (a) using PID controller; (b) using $\mathcal{H}_{\infty}$ controller; and (c) using $\mu$ controller. (d), (e) and (f) show the control action in response to the impulse disturbance.

seen in Fig. 16a. Stability and performance issues arise as the pressure is applied since this decentralized controller structure does not compensate for cross coupled seal forces. This is seen as oscillations in Fig. 15d.

2. The $\mathcal{H}_{\infty}$ shows good performance for the nominal design point where a fixed pressure across the seal is applied as seen in Fig. 15e. The settling time of approximately $0.03 \mathrm{~s}$ is very similar to the settling of the PID controller without pressure applied. The displacement in $A_{\zeta}$ and $B_{\zeta}$ is equal since the $\mathcal{H}_{\infty}$ controller synthesis accounts for the flexible coupling and the different $K_{i}$ and $K_{s}$ values of the two bearings. Stability problems can be detected when using this controller for the case of zero pressure across the seal. Such a claim can be reinforced by Fig. $15 b$.

3. The $\mu$ controller shows very similar performance as the $\mathcal{H}_{\infty}$ controller when the pressure drop across the gas seal is 2.04 bar. Such a similarity in terms of overshoot as well as settling time is depicted in Fig. 15e, even though the cross coupling effects due to the aerodynamic seal forces are handled slightly differently. For the case of no pressure drop across the seal, an improvement in terms of settling time, stabilization and reduction of oscillating behaviour is seen when using the $\mu$ compared to the $\mathcal{H}_{\infty}$ controller. Hence the $\mu$ controller is more robust to changes of pressures across the seal.

\section{Conclusion}

This paper demonstrates the capabilities of three types of controllers, both theoretically and experimentally, in addressing and compensating for rotor lateral vibrations induced by destabilising aerodynamic seal forces. Numerical simulations of rotor lateral dynamics are carried out using identified mathematical models. Experiments are conducted using the synthesised controllers applied to the test facility. Comparison between theoretical and experimental results agrees very well, allowing us to conclude that:

i) The designed $\mathcal{H}_{\infty}$ controller shows significant performance improvements when the rotor-bearing-seal system operates close to design pressure conditions, i.e. pressure drop across the gas seal around 2.04 bar. However, when the pressure drop across the seal changes from the nominal one, the performance of the controller is reduced, once the identified model used to synthesize the controller is no longer able to accurately predict the dynamics of the rotor-bearing-seal system (plant). Specifically, a decreased performance is observed when the pressure drop across the seal is lower than the nominal condition. ii) Using the perturbed plant formulation and $\mu$ synthesis to design robust controllers, it is shown to be possible to optimize and improve the worst case performance over a larger pressure range. The synthesised $\mu$ controller is able to handle pressure variations better than the $\mathcal{H}_{\infty}$ controller.

iii) Since the controller gains, and thus the direct stiffness and damping coefficients of the AMBs are cost parame- 


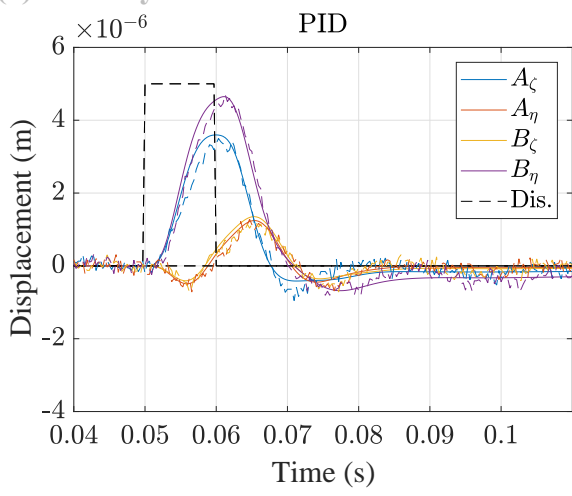

(a)

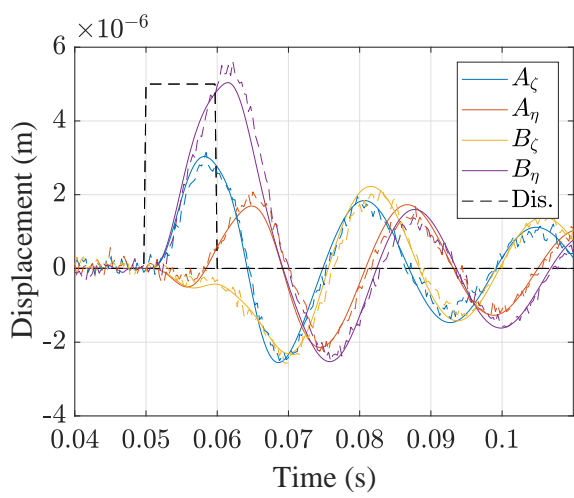

(d)

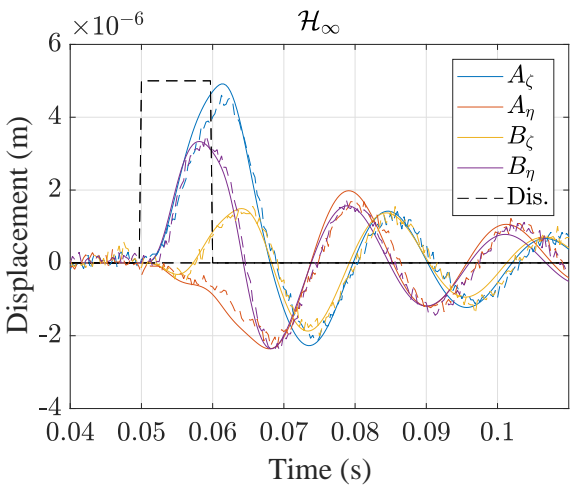

(b)

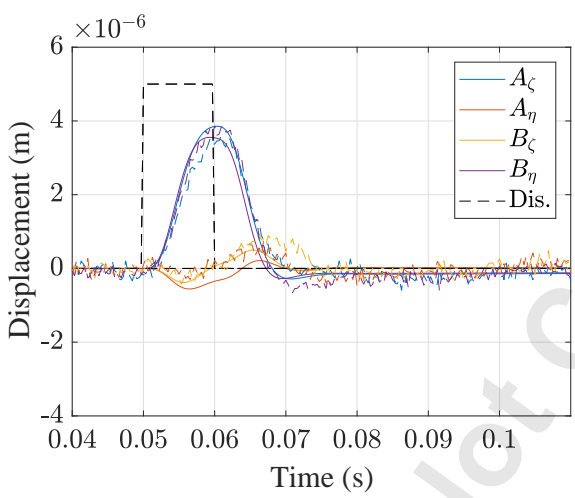

(e)

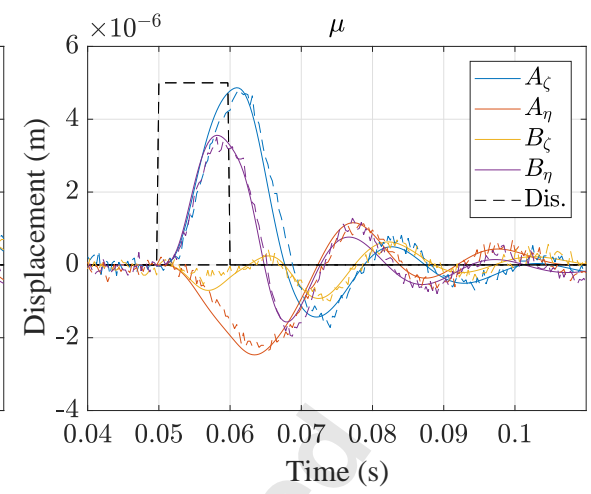

(c)

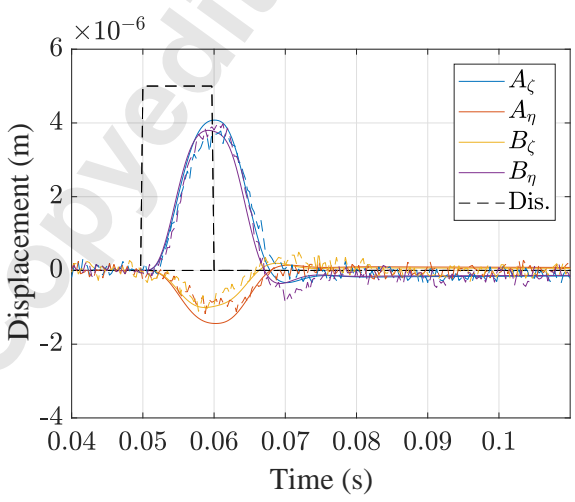

(f)

Fig. 15: Impulse response of plant in $A_{\zeta}$ and $B_{\eta}$ direction: (a) and (d) using PID controller; (b) and (e) using $\mathcal{H}_{\infty}$ controller; and (c) and (d) using $\mu$ controller. (a), (b) and (c) show the response when no pressure is applied. (d), (e) and (f) show the response when 2.04 bar pressure is applied. Simulated responses are shown as solid lines and experimental responses are marked with '- - '. Current impulsive setpoint disturbance from $0.05 \mathrm{~s}$ to $0.06 \mathrm{~s}$ is scaled in amplitude and shown as the dashed line 'Dis.'.

ters, they are kept approximately constant for all three types of controllers, namely PID, $\mathcal{H}_{\infty}$ and $\mu$. The parameters subjected to changes are only the gas seals force coefficients due to pressure drop variations. The seal force coefficients are quite high compared to the force coefficients of the AMBs. The theoretical and experimental investigations were carried out in such a way to emphasise the difference in performance of the controllers with similar gains. A slightly more realistic approach would be to increase the controller gain or the size of the AMBs to obtain larger values of direct stiffness and damping. This would immediately increase robustness and stability followed by significant improvement in system performance.

iv) Finalizing, this paper has presented a structured way to design robust controllers to deal with uncertain/varying seal forces, including the tuning of the weighting functions. It is shown that the robust controller synthesis deals with finding a non-conservative controller that will guarantee robust performance while at the same time keeping the controller gains moderate. The method could potentially be implemented in any AMB based systems subjected to seal or other fluid film forces.

\section{A The System Matrices}

The system matrices for the nominal plant in section 3 and perturbed plant in 3.2 are given as 


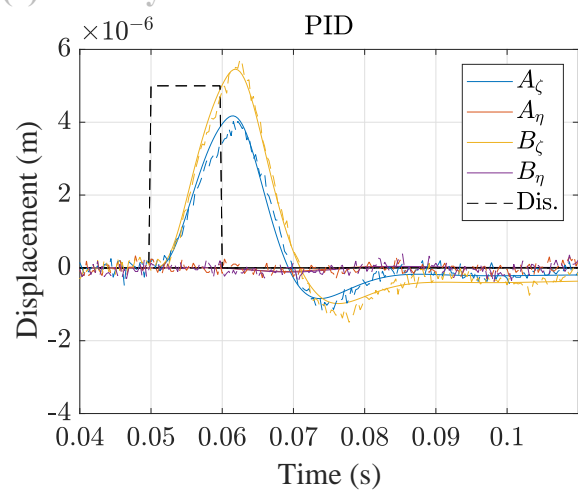

(a)

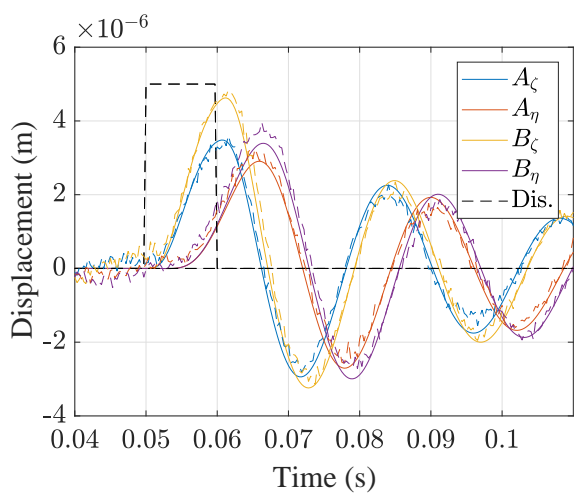

(d)

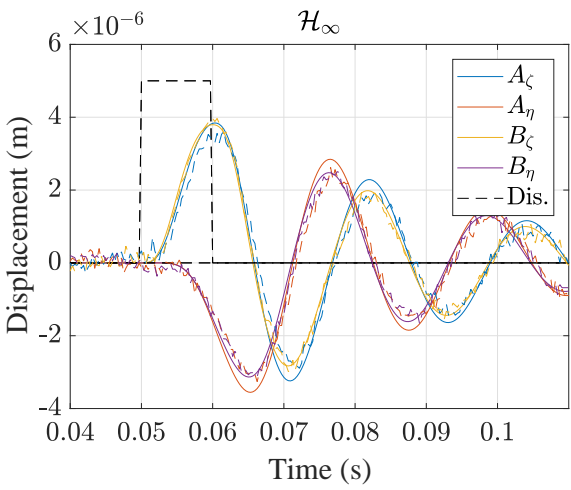

(b)

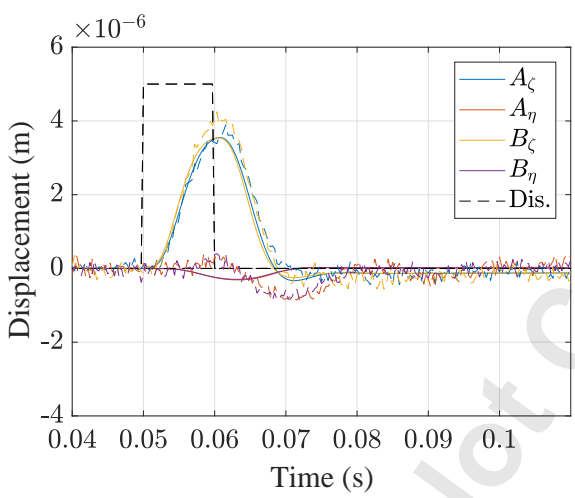

(e)

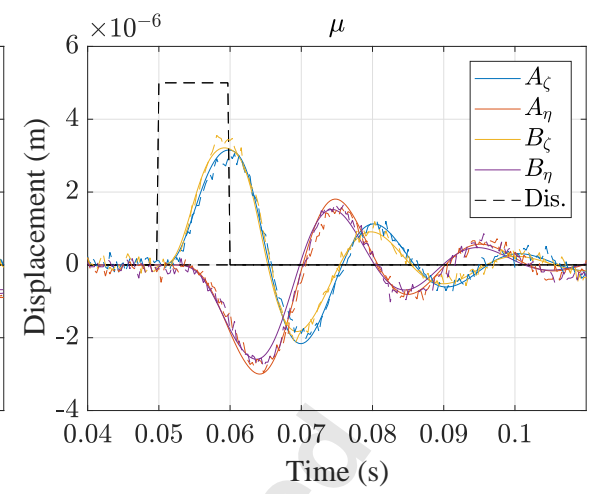

(c)

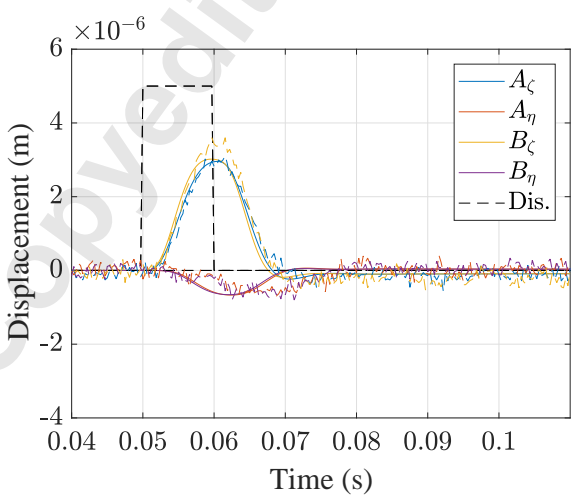

(f)

Fig. 16: Impulse response of plant in $A_{\zeta}$ and $B_{\zeta}$ direction: (a) and (d) using PID controller; (b) and (e) using $\mathcal{H}_{\infty}$ controller; and (c) and (d) using $\mu$ controller. (a), (b) and (c) show the response when no pressure is applied. (d), (e) and (f) show the response when 2.04 bar pressure is applied. Simulated responses are shown as solid lines and experimental responses are marked with '- - '. Current impulsive setpoint disturbance from $0.05 \mathrm{~s}$ to $0.06 \mathrm{~s}$ is scaled in amplitude and shown as the dashed line 'Dis.'.

$$
A=\left[\begin{array}{cccccccc}
-111 & -166 & 130 & 84.6 & 8.07 & -8.07 & -2.81 & -2.81 \\
155 & 100 & 130 & 84.6 & 8.07 & -8.07 & -2.81 & -2.81 \\
-132 & 86.2 & -261 & 67.7 & -3.56 & 3.55 & -4.62 & -4.62 \\
132 & -86.2 & -4.56 & 198 & 3.56 & -3.55 & 4.62 & 4.62 \\
86.7 & -86.7 & -52.5 & -52.6 & -180 & -117 & -0.11 & -0.108 \\
86.8 & -86.8 & -52.6 & -52.6 & 118 & 180 & -0.108 & -0.106 \\
64.1 & -64.1 & 148 & 148 & -0.934 & 0.861 & 182 & -116 \\
-64.1 & 64.1 & -148 & -148 & 0.86 & -0.787 & 116 & -182
\end{array}\right]
$$$$
B=\left[\begin{array}{cccc}
-1.716 \times 10^{-2} & 5.470 \times 10^{-2} & -1.716 \times 10^{-2} & 5.470 \times 10^{-2} \\
-1.716 \times 10^{-2} & 5.469 \times 10^{-2} & -1.716 \times 10^{-2} & 5.469 \times 10^{-2} \\
-3.508 \times 10^{-2} & -4.534 \times 10^{-2} & -3.508 \times 10^{-2} & -4.534 \times 10^{-2} \\
3.508 \times 10^{-2} & 4.533 \times 10^{-2} & 3.508 \times 10^{-2} & 4.533 \times 10^{-2} \\
1.276 \times 10^{-2} & 2.533 \times 10^{-1} & -1.276 \times 10^{-2} & -2.533 \times 10^{-1} \\
1.277 \times 10^{-2} & 2.534 \times 10^{-1} & -1.277 \times 10^{-2} & -2.534 \times 10^{-1} \\
-2.265 \times 10^{-1} & -1.142 \times 10^{-1} & 2.265 \times 10^{-1} & 1.142 \times 10^{-1} \\
2.265 \times 10^{-1} & 1.140 \times 10^{-1} & -2.265 \times 10^{-1} & -1.140 \times 10^{-1}
\end{array}\right]
$$

$$
C^{T}=\left[\begin{array}{cccc}
4.654 \times 10^{-4} & -3.601 \times 10^{-4} & 4.654 \times 10^{-4} & -3.601 \times 10^{-4} \\
-4.653 \times 10^{-4} & 3.602 \times 10^{-4} & -4.653 \times 10^{-4} & 3.602 \times 10^{-4} \\
5.615 \times 10^{-4} & 1.761 \times 10^{-4} & 5.615 \times 10^{-4} & 1.761 \times 10^{-4} \\
5.614 \times 10^{-4} & 1.762 \times 10^{-4} & 5.614 \times 10^{-4} & 1.762 \times 10^{-4} \\
8.229 \times 10^{-5} & -1.635 \times 10^{-4} & -8.229 \times 10^{-5} & 1.635 \times 10^{-4} \\
-8.238 \times 10^{-5} & 1.634 \times 10^{-4} & 8.238 \times 10^{-5} & -1.634 \times 10^{-4} \\
-1.828 \times 10^{-4} & 9.214 \times 10^{-6} & 1.828 \times 10^{-4} & -9.214 \times 10^{-6} \\
-1.828 \times 10^{-4} & 9.211 \times 10^{-6} & 1.828 \times 10^{-4} & -9.211 \times 10^{-6}
\end{array}\right]
$$

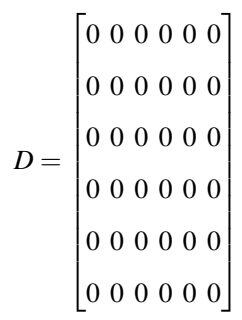


Journal of Dynamic Systems, Measurement and Control. Received May 16, 2017;

Accepted manuscript posted March 21, 2018. doi:10.1115/1.4039665

Copyright (c) 2018 by ASME

$$
B_{\Delta}=\left[\begin{array}{cc}
5.522 \times 10^{4} & 1.760 \times 10^{5} \\
5.524 \times 10^{4} & 1.760 \times 10^{5} \\
1.129 \times 10^{5} & -1.459 \times 10^{5} \\
-1.129 \times 10^{5} & 1.459 \times 10^{5} \\
-2.736 \times 10^{-3} & -8.407 \times 10^{-3} \\
-2.729 \times 10^{-3} & -8.418 \times 10^{-3} \\
-5.877 \times 10^{-3} & -1.426 \times 10^{-3} \\
5.885 \times 10^{-3} & 1.438 \times 10^{-3}
\end{array}\right]
$$$$
C_{\Delta}^{T}=\left[\begin{array}{cc}
-3.584 \times 10^{-4} & 4.632 \times 10^{-4} \\
3.585 \times 10^{-4} & -4.631 \times 10^{-4} \\
1.753 \times 10^{-4} & 5.588 \times 10^{-4} \\
1.754 \times 10^{-4} & 5.588 \times 10^{-4} \\
1.049 \times 10^{-12} & 1.432 \times 10^{-13} \\
-1.047 \times 10^{-12} & -1.446 \times 10^{-13} \\
-1.888 \times 10^{-13} & -3.178 \times 10^{-13} \\
-1.894 \times 10^{-13} & -3.160 \times 10^{-13}
\end{array}\right]
$$

$$
\Delta=\left[\begin{array}{cc}
\delta_{1} & 0 \\
0 & \delta_{1}
\end{array}\right],\left|\delta_{1}\right|<1
$$




\section{Copyright (c) 2018 bo bontroller Statespace Matrices}

C $\mathcal{H}_{\infty}$ Controller

$B=\left[\begin{array}{cccc}-3.705 & 7.297 & 4.803 & 9.525 \\ -6.587 & -9.528 & 3.470 \times 10^{-1} & 7.900 \\ 7.240 & -3.190 \times 10^{-1} & -5.397 & 7.324 \\ -2.300 \times 10^{-1} & 9.377 & -9.378 & -7.295 \\ 2.246 & -4.358 & 3.180 \times 10^{-1} & 3.946 \\ 4.261 & 2.135 & -3.835 & 2.420 \times 10^{-1} \\ 1.622 & -6.690 \times 10^{-1} & 1.318 & -1.769 \\ 6.680 \times 10^{-1} & 1.634 & 1.733 & 1.285 \\ 9.743 & -2.052 \times 10^{1} & 1.707 & 1.860 \times 10^{1} \\ 2.029 \times 10^{1} & 9.249 & -1.812 \times 10^{1} & 1.437 \\ -7.117 & 1.320 & -6.848 & 6.251 \\ 1.305 & 7.034 & 6.111 & 6.741 \\ 1.140 & 1.800 \times 10^{-2} & -1.530 & 0.000 \\ 0.000 & 1.070 & 1.400 \times 10^{-2} & -1.543 \\ -7.710 \times 10^{-1} & -2.930 \times 10^{-1} & -8.130 \times 10^{-1} & -1.990 \times 10^{-1} \\ -2.930 \times 10^{-1} & 7.640 \times 10^{-1} & -1.940 \times 10^{-1} & 7.690 \times 10^{-1} \\ 5.460 \times 10^{-1} & 1.270 \times 10^{-1} & -6.900 \times 10^{-1} & 2.800 \times 10^{-1} \\ 1.050 \times 10^{-1} & -4.990 \times 10^{-1} & 2.670 \times 10^{-1} & 7.020 \times 10^{-1} \\ -5.570 \times 10^{-1} & -1.560 \times 10^{-1} & -8.780 \times 10^{-1} & -1.410 \times 10^{-1} \\ -1.500 \times 10^{-1} & 5.430 \times 10^{-1} & -1.430 \times 10^{-1} & 8.640 \times 10^{-1}\end{array}\right]$

$C^{T}=\left[\begin{array}{cccc}-4.587 \times 10^{2} & 2.548 \times 10^{2} & 7.269 \times 10^{2} & 5.248 \times 10^{2} \\ -3.563 \times 10^{2} & -5.871 \times 10^{2} & -6.740 \times 10^{2} & 9.188 \times 10^{2} \\ 9.618 \times 10^{2} & -5.935 \times 10^{2} & -1.936 \times 10^{3} & 1.277 \times 10^{3} \\ 1.820 \times 10^{2} & 2.838 \times 10^{2} & -1.450 \times 10^{3} & -6.449 \times 10^{2} \\ 1.234 \times 10^{1} & 8.350 \times 10^{1} & 1.754 \times 10^{1} & -1.376 \times 10^{2} \\ -8.619 \times 10^{1} & 1.218 \times 10^{1} & 1.407 \times 10^{2} & 1.652 \times 10^{1} \\ 3.338 & 4.289 & 6.950 \times 10^{-1} & 5.429 \times 10^{1} \\ -3.833 & 2.517 & -5.538 \times 10^{1} & 6.740 \times 10^{-1} \\ 1.044 \times 10^{1} & 1.366 \times 10^{2} & 3.993 \times 10^{1} & -2.239 \times 10^{2} \\ -1.430 \times 10^{2} & 1.081 \times 10^{1} & 2.313 \times 10^{2} & 3.845 \times 10^{1} \\ 1.189 & -1.673 & -6.310 & -9.959 \times 10^{1} \\ -7.620 \times 10^{-1} & -2.605 & -1.024 \times 10^{2} & 6.775 \\ 4.032 & -6.230 \times 10^{-1} & -9.047 & -4.650 \times 10^{-1} \\ 6.110 \times 10^{-1} & 3.613 & 3.650 \times 10^{-1} & -8.645 \\ -1.152 & -3.520 \times 10^{-1} & -4.106 & 3.040 \\ -3.320 \times 10^{-1} & 1.244 & 3.121 & 3.726 \\ 2.648 & -1.450 \times 10^{-1} & -4.128 & 1.846 \\ -1.380 \times 10^{-1} & -2.493 & 1.818 & 4.064 \\ 3.620 \times 10^{-1} & -2.000 \times 10^{-3} & 8.490 \times 10^{-1} & -3.036 \\ 1.600 \times 10^{-2} & -4.020 \times 10^{-1} & -3.132 & -8.630 \times 10^{-1}\end{array}\right]$

$$
D=\left[\begin{array}{llll}
0 & 0 & 0 & 0 \\
0 & 0 & 0 & 0 \\
0 & 0 & 0 & 0 \\
0 & 0 & 0 & 0
\end{array}\right]
$$




$B=\left[\begin{array}{cccc}0.000 & 0.000 & 0.000 & 1.000 \times 10^{-3} \\ 0.000 & 0.000 & 0.000 & 0.000 \\ 5.988 \times 10^{1} & 1.966 \times 10^{2} & 2.715 \times 10^{1} & 3.150 \times 10^{2} \\ -2.655 \times 10^{2} & 1.303 \times 10^{3} & -3.392 \times 10^{2} & 1.572 \times 10^{3} \\ -2.224 \times 10^{2} & -9.787 \times 10^{1} & -2.878 \times 10^{2} & -1.945 \times 10^{2} \\ 9.787 \times 10^{2} & 1.046 \times 10^{3} & 1.129 \times 10^{3} & 1.264 \times 10^{3} \\ 4.725 \times 10^{1} & 8.134 \times 10^{2} & -6.440 \times 10^{1} & -1.320 \times 10^{3} \\ 2.685 \times 10^{2} & 5.001 \times 10^{3} & -2.938 \times 10^{2} & -5.984 \times 10^{3} \\ -4.589 \times 10^{3} & -2.247 \times 10^{3} & 5.369 \times 10^{3} & 2.704 \times 10^{3} \\ 7.822 \times 10^{2} & 3.594 \times 10^{2} & -1.192 \times 10^{3} & -6.008 \times 10^{2} \\ 2.000 \times 10^{-3} & 0.000 & 0.000 & 0.000 \\ 0.000 & 2.000 \times 10^{-3} & 0.000 & 0.000 \\ 0.000 & 0.000 & 2.000 \times 10^{-3} & 0.000 \\ 0.000 & 0.000 & 0.000 & 2.000 \times 10^{-3} \\ -3.000 \times 10^{-3} & 0.000 & 1.000 \times 10^{-3} & 0.000 \\ 1.000 \times 10^{-3} & 0.000 & 0.000 & 0.000 \\ 0.000 & -3.000 \times 10^{-3} & 0.000 & 1.000 \times 10^{-3} \\ 0.000 & 1.000 \times 10^{-3} & 0.000 & 0.000 \\ 1.000 \times 10^{-3} & 0.000 & -3.000 \times 10^{-3} & 0.000 \\ 0.000 & 0.000 & 2.000 \times 10^{-3} & 0.000 \\ 0.000 & 1.000 \times 10^{-3} & 0.000 & -3.000 \times 10^{-3} \\ 0.000 & 0.000 & 0.000 & 2.000 \times 10^{-3} \\ -1.000 \times 10^{-3} & 0.000 & -1.000 \times 10^{-3} & 0.000 \\ 0.000 & 1.000 \times 10^{-3} & 0.000 & 1.000 \times 10^{-3}\end{array}\right]$

$\left[\begin{array}{cccc}-2.325 \times 10^{1} & 1.843 \times 10^{3} & 2.700 \times 10^{2} & 3.132 \times 10^{3} \\ 3.106 \times 10^{3} & 4.026 \times 10^{3} & 5.543 \times 10^{3} & 5.674 \times 10^{3} \\ 1.884 & 2.001 & 3.313 & 2.589 \\ -4.456 & -1.377 & -7.122 & -1.309 \\ 2.288 & 3.517 & 4.228 & 5.069 \\ 1.013 \times 10^{1} & 1.220 \times 10^{1} & 1.735 \times 10^{1} & 1.716 \times 10^{1} \\ 4.100 \times 10^{-2} & 5.200 \times 10^{-2} & 2.000 \times 10^{-2} & 1.780 \times 10^{-1} \\ -2.070 \times 10^{-1} & 2.180 \times 10^{-1} & 2.250 \times 10^{-1} & -7.790 \times 10^{-1} \\ -9.600 \times 10^{-2} & 3.960 \times 10^{-1} & 1.169 & 4.860 \times 10^{-1} \\ 5.500 \times 10^{-2} & 8.800 \times 10^{-2} & 2.170 \times 10^{-1} & 1.150 \times 10^{-1} \\ 1.781 \times 10^{4} & 1.346 \times 10^{4} & 1.936 \times 10^{4} & 1.858 \times 10^{4} \\ 8.702 \times 10^{3} & 2.128 \times 10^{4} & 1.568 \times 10^{4} & 2.167 \times 10^{4} \\ 1.587 \times 10^{4} & 1.912 \times 10^{4} & 3.661 \times 10^{4} & 2.642 \times 10^{4} \\ 1.109 \times 10^{4} & 1.966 \times 10^{4} & 2.012 \times 10^{4} & 3.793 \times 10^{4} \\ 5.502 \times 10^{4} & 3.234 \times 10^{4} & 4.778 \times 10^{4} & 4.374 \times 10^{4} \\ 1.101 \times 10^{5} & 6.871 \times 10^{4} & 9.705 \times 10^{4} & 9.343 \times 10^{4} \\ 3.234 \times 10^{4} & 7.508 \times 10^{4} & 5.753 \times 10^{4} & 7.053 \times 10^{4} \\ 6.038 \times 10^{4} & 1.439 \times 10^{5} & 1.079 \times 10^{5} & 1.333 \times 10^{5} \\ 4.778 \times 10^{4} & 5.753 \times 10^{4} & 1.241 \times 10^{5} & 7.861 \times 10^{4} \\ 9.892 \times 10^{4} & 1.223 \times 10^{5} & 2.558 \times 10^{5} & 1.675 \times 10^{5} \\ 4.374 \times 10^{4} & 7.053 \times 10^{4} & 7.861 \times 10^{4} & 1.439 \times 10^{5} \\ 5.592 \times 10^{4} & 1.401 \times 10^{5} & 1.550 \times 10^{5} & 2.878 \times 10^{5} \\ -3.550 \times 10^{3} & -6.553 \times 10^{3} & 8.049 \times 10^{3} & 6.224 \times 10^{3} \\ & & & -9.079 \times 10^{3}\end{array}\right]$

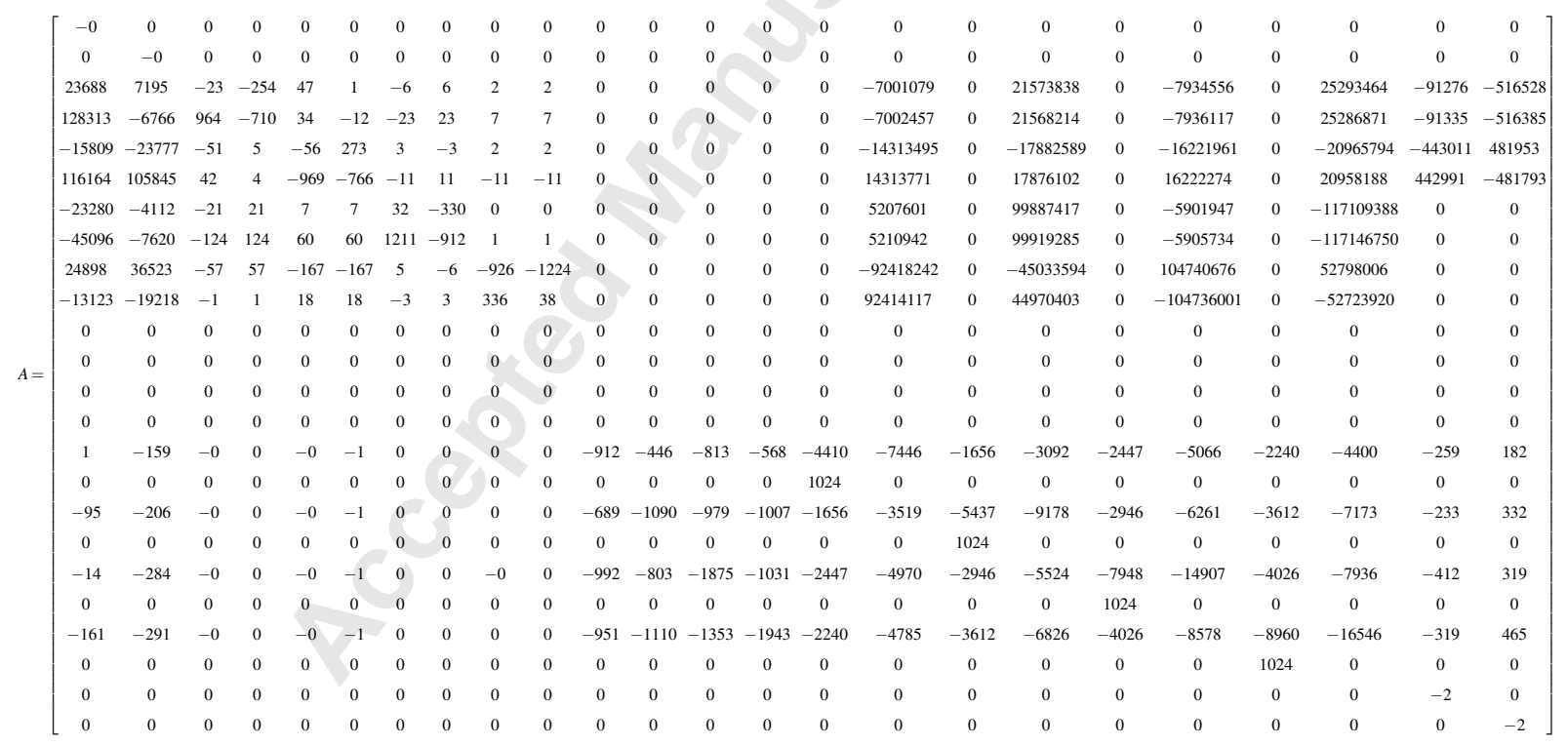

$$
D=\left[\begin{array}{llll}
0 & 0 & 0 & 0 \\
0 & 0 & 0 & 0 \\
0 & 0 & 0 & 0 \\
0 & 0 & 0 & 0
\end{array}\right]
$$




\section{Copyright Reŕerences}

[1] Fritz, R., 1970. "The effects of an annular fluid on the vibrations of a long rotor, part 1theory". Journal of Fluids Engineering, 92, pp. 923-929.

[2] Black, H., 1969. "Effects of hydraulic forces in annular pressure seals on the vibrations of centrifugal pump rotors". Journal of Mechanical Engineering Science, 11(2), pp. 206-213.

[3] Black, H., and Jenssen, D., 1970. "Dynamic hybrid properties of annular pressure seals". Journal of Fluids Engineering, 184, pp. 92-100.

[4] Childs, D. W., and Dressman, J. B., 1982. "Testing of turbulent seals for rotordynamic coefficients". In Proc. Workshop on Rotordynamic Instability Problems in High-Performance Turbomachinery, NASA Conf. Publ. 2250, pp. 157-171.

[5] Nordmann, R., and Massmann, H., 1984. "Identification of dynamic coefficients of annular turbulent seals". In Proc. Workshop on Rotordynamic Instability Problems in High-Performance Turbomachinery, NASA Conf. Publ. 2338, pp. 295-311.

[6] Baskharone, E., and Hensel, S., 1993. "Flow field in the secondary, seal-containing passages of centrifugal pumps". Journal of Fluids Engineering, 115, pp. 702 702.

[7] Schettel, J., and Nordmann, R., 2004. "Rotordynamics of turbine labyrinth seals - a comparison of cfd models to experiments". Imeche Conference Transactions, 2004(2), pp. 13-22.

[8] Ishii, E., Chisachi, K., Kikuchi, K., and Ueyama, Y., 1997. "Prediction of rotordynamic forces in a labyrinth seal based on three-dimensional turbulent flow computation”. Machine Elements and Manufacturing, 40(4), pp. 743-748.

[9] Rhode, D. L., Hensel, S. J., and Guidry, M. J., 1992. "Labyrinth seal rotordynamic forces using a threedimensional navier-stokes code". Journal of Tribology, 114(4), p. 683.

[10] Hirs, G., 1973. "A bulk-flow theory for turbulence in lubricant films". ASME J. Lubr. Technol, pp. 137-146.

[11] Childs, D., 1989. "Fluid-structure interaction forces at pump-impeller-shroud surfaces for rotordynamic calculations". Journal of Vibration, Acoustics, Stress, and Reliability in Design, 111, pp. 216-225.

[12] Nielsen, K. K., Jønck, K., and Underbakke, H., 2012. "Hole-pattern and honeycomb seal rotordynamic forces: Validation of cfd-based prediction techniques". Journal of Engineering for Gas Turbines and Power, 134(12), p. 122505.

[13] Marquette, O., Childs, D., and SanAndres, L., 1997. "Eccentricity effects on the rotordynamic coefficients of plain annular seals: Theory versus experiment". Journal of Tribology, 119(3), pp. 443-447.

[14] Hsu, Y., and Brennen, C., 2002. "Fluid flow equations for rotordynamic flows in seals and leakage paths". Journal of Fluids Engineering, 124(1), pp. 176-181.

[15] Kirk, R., and Guo, Z., 2004. "Calibration of labyrinth seal bulk flow design analysis predictions to cfd simu- lation results". In Eighth International Conference on Vibrations in Rotating Machinery, pp. 3-12.

[16] Kocur, J. A., Nicholas, J. C., and Lee, C. C., 2007. "Surveying tilting pad journal bearing and gas labyrinth seal coefficients and their effect on rotor stability". In 36th Turbomachinery Symposium, Turbomachinery Laboratory, Texas A\&M University, College Station, TX, September, pp. 10-13.

[17] San Andrés, L., 2012. "Rotordynamic force coefficients of bubbly mixture annular pressure seals". Journal of Engineering for Gas Turbines and Power, 134(2), p. 022503.

[18] Cole, M. O., Keogh, P. S., Sahinkaya, M. N., and Burrows, C. R., 2004. "Towards fault-tolerant active control of rotor-magnetic bearing systems". Control Engineering Practice, 12(4), pp. 491-501.

[19] Balas, G. J., and Young, P. M., 1995. "Control design for variations in structural natural frequencies". Journal of Guidance, Control, and Dynamics, 18(2), pp. 325-332.

[20] Schonhoff, U., Luo, J., Li, G., Hilton, E., Nordmann, R., and Allaire, P., 2000. "Implementation results of mu-synthesis control for an energy storage flywheel test rig". In Proceedings of ISMB8.

[21] Zhou, K., Doyle, J. C., Glover, K., et al., 1996. Robust and optimal control, Vol. 40. Prentice hall New Jersey.

[22] ISO, S., 2004. "Mechanical vibration-vibration of rotating machinery equipped with active magnetic bearings-part 3: Evaluation of stability margin". ISO 14839-3: $2006(E)$.

[23] Cole, M., Chamroon, C., and Keogh, P., 2016. "Hinfinity controller design for active magnetic bearings considering nonlinear vibrational rotordynamics". In Proceedings of ISMB15.

[24] Balini, H., Witte, J., and Scherer, C. W., 2012. "Synthesis and implementation of gain-scheduling and $\mathrm{lpv}$ controllers for an amb system". Automatica, 48(3), pp. 521-527.

[25] Mushi, S. E., Lin, Z., Allaire, P. E., and Evans, S., 2008. "Aerodynamic cross-coupling in a flexible rotor: Control design and implementation". In Proceedings of ISMB11.

[26] Wurmsdobler, P., 1997. "State space adaptive control for a rigid rotor suspended in active magnetic bearings". PhD thesis, TU Wien.

[27] Lang, O., Wassermann, J., and Springer, H., 1996. "Adaptive vibration control of a rigid rotor supported by active magnetic bearings". Journal of engineering for gas turbines and power, 118(4), pp. 825-829.

[28] Hirschmanner, M., and Springer, H., 2002. "Adaptive vibration and unbalance control of a rotor supported by active magnetic bearings". In Proceedings of ISMB8.

[29] Lauridsen, J., and Santos, I., 2017. "Design of robust amb controllers for rotors subjected to varying and uncertain seal forces". Mechanical Engineering Journal, pp. 16-00618.

[30] Lauridsen, J. S., and Santos, I. F., 2018. "On-site identification of dynamic annular seal forces in turbo machi- 
Copyright (c) 2018 nery using active magnetic bearings - an experimental investigation". Journal of Engineering for Gas Turbines and Power.

[31] Voigt, A. J., Mandrup-Poulsen, C., Nielsen, K. K., and Santos, I. F., 2017. "Design and calibration of a full scale active magnetic bearing based test facility for investigating rotordynamic properties of turbomachinery seals in multiphase flow". Journal of Engineering for Gas Turbines and Power, 139(5), p. 052505.

[32] Voigt, A. J., 2016. "Towards identification of rotordynamic properties for seals in multiphase flow using active magnetic bearings. design and commissioning of a novel test facility". PhD thesis, Technical University of Denmark.

[33] Bleuler, H., Cole, M., Keogh, P., Larsonneur, R., Maslen, E., Okada, Y., Schweitzer, G., and Traxler, A., 2009. Magnetic bearings: theory, design, and application to rotating machinery. Springer-Verlag Berlin Heidelberg.

[34] Childs, D. W., 1993. Turbomachinery rotordynamics: phenomena, modeling, and analysis. Wiley New York.

[35] Nelson, H., 1980. "A finite rotating shaft element using timoshenko beam theory". Journal of Mechanical Design, 102(4), pp. 793-803.

[36] Skogestad, S., and Postlethwaite, I., 2007. Multivariable feedback control: analysis and design, Vol. 2. Wiley New York.

[37] Voigt, A. J., Lauridsen, J. S., Poulsen, C. M., Nielsen, K. K., and Santos, I. F., 2016. "Identification of parameters in active magnetic bearing systems". In Proceedings of ISMB 15. 